\title{
Hubungan Keanekaragaman dan Keberadaan Plankton Terhadap Faktor Fisika Kimia Sungai Batanghari
}

\author{
Marhadi*, Ira Galih Prabasari, Ria Pratiwi \\ Program Studi Teknik Lingkungan Universitas Batanghari \\ *e-mail : marhadi54@yahoo.co.id
}

\begin{abstract}
ABSTRAK
Pencemaran air tidak hanya dapat diukur hanya dengan parameter kimia dan fisika, Plankton mempunyai sifat yang selalu bergerak sehingga dapat dijadikan indikator pencemaran air. Plankton memegang peranan penting dalam mempengaruhi produktifitas primer perairan sungai.Tujuan penelitian ini adalah untuk mengetahui adanya hubungan keanekaragaman dan keberadaan plankton terhadap kualitas Sungai Batanghari. Penelitian dilakukan pada bulan Februari 2018 di Kota Jambi.Data primer yang diambil berupa konsentrasi parameter fisika dan kimia meliputi kekeruhan, pH, TDS, BOD, COD, DO, Fosfat, Nitrat, Nitrit, Amoniak, Timbal, Klorida, Sulfat serta jumlah kelimpahan plankton (ind/L) pada Sungai Batanghari. Data sekunder yang diambil berupa data panjang Sungai Batanghari wilayah Kota Jambi dan baku mutu sungai batanghari PP 82 Tahun 2001. Waktu pengambilan sampel yaitu pada pagi dan sore hari di hari yang sama. Hasil penelitian menunjukkan bahwa hubungan antara keberadaan plankton dengan kualitas Sungai Batanghari menunjukkan kondisi Sungai Batanghari Kota Jambi berada di fase $\alpha$ - Mesosaprobik (tingkat pencemar berat). Parameter pH, COD, Fosfat, Nitrit, Timbal dan Klorida berkorelasi sedang terhadap fitoplankton, sedangkan TDS, BOD, DO, Nitrat dan Amoniak berkorelasi lemah terhadap fitoplankton. Dan untuk parameter suhu berkorelasi kuat terhadap fitoplankton. Untuk korelasi terhadap zooplankton, parameter pH, TDS, BOD, COD, COD, DO, Fosfat, Nitrat, Nitrit, Timbal, klorida berkorelasi sangat lemah sedangkan amoniak dan kekeruhan berkorelasi sedang terhadap zooplankton.
\end{abstract}

Kata kunci : Plankton; Parameter fisika kimia air; Sungai Batanghari.

\begin{abstract}
Water pollution can not only be measured only by chemical and physical parameters, Plankton have properties that are always moving so that they can be used as indicators of water pollution. Plankton play an important role in influencing the primary productivity of river waters. The purpose of this study was to determine the relationship between the diversity and presence of plankton to the quality of the Batanghari River. The study was conducted in February 2018 in Jambi City. Primary data taken in the form of concentrations of physical and chemical parameters include turbidity, pH, TDS, BOD, COD, DO, Phosphate, Nitrate, Nitrite, Ammonia, Lead, Chloride, Sulfate and the amount of plankton abundance (ind / L) on the Batanghari River. The time of sampling was in the morning and evening on the same day. The results showed that the relationship between the existence of plankton and the quality of the Batanghari River showed the condition of the Batanghari River in Jambi City was in phase $\alpha$ - Mesosaprobic (heavy pollutant level). Parameters of $\mathrm{pH}$, COD, Phosphate, Nitrite, Lead and Chloride are moderately correlated to phytoplankton, while TDS, BOD, DO, Nitrate and Ammonia are weakly correlated with phytoplankton. And for temperature parameters it is strongly correlated with phytoplankton. For correlation to zooplankton, parameters of $\mathrm{pH}$, TDS, BOD, COD, COD, DO, Phosphate, Nitrate, Nitrite, Lead, chloride are very weakly correlated while ammonia and turbidity correlate moderately to zooplankton.
\end{abstract}

Keywords: Batanghari River; Plankton; Water chemistry physical parameters.

\section{Pendahuluan}

Sungai Batanghari Kota Jambi memiliki panjang \pm $11 \mathrm{~km}$. Hulunya berada di Jembatan Aur Duri I dan mengalir ke arah timur ke Jembatan Aur Duri II. Kualitas Sungai Batanghari saat ini berdasarkan kegiatan pemantauan yang dilakukan dalam waktu persemester menunjukkan bahwa air Sungai Batanghari masih di kategori kelas II untuk air baku berdasarkan Peraturan Pemerintah No 82 Tahun 2001 (DLH Provinsi Jambi, 2017).

Permasalahan utama yang dialami ekosistem Sungai Batanghari adalah penurunan kualitas air sebagai akibat dari limbah cair domestik pemukiman yang dibuang ke dalam sungai sehingga menimbulkan pencemaran air sungai.
Penelitian mengenai keanekaragaman plankton suatu badan perairan senantiasa banyak mendapat perhatian dari para ahli yang berkecimpung dalam bidang limnology dan oseanografi. Keanekaragaman Plankton yaitu suatu struktur komunitas plankton di suatu perairan, kenaekaragaman pada plankton juga dapat menentukan jumlah spesies atau kelimpahan spesies serta menentukan keseimbangan komunitas plankton tersebut. Karena dengan mengetahui keanekaragaman plankton yang dimiliki oleh suatu ekosistem perairan maka akan dapat diketahui keberadaan dari spesies-spesies plankton yang ada di suatu perairan dan dapat juga mengetahui tingkat kesuburan dari perairan tersebut, apakah termasuk dalam kategori eutrofik, mesotrofik atau oligotrofik (Lehmusluoto, 1977 ; Odum, 1994). 
Plankton merupakan suatu organisme yang hanyut bebas didalam air dan memiliki daya renang sangat lemah. Plankton terdiri dari dua golongan yakni fitoplankton dan zooplankton. Fitoplankton merupakan tumbuhan renik yang bebas melayang dan hanyut dalam air serta mampu berfotosintesis.Sedangkan zooplankton merupakan hewan air yang berukuran renik, dapat ditemukan didalam air tawar maupun air laut (Nybakken, 1992). Menurut Riyadi (1984) ada beberapa parameter yang digunakan dalam pengukuran kualitas air yakni meliputi sifat fisik dan kimia. Adapun parameter fisika yang mempengaruhi diantaranya Suhu dan Padatan Terlarut (TDS) sedangkan parameter kimia yang mempengaruhi yaitu Derajat Keasaman $(\mathrm{pH})$, BOD, COD, DO, Fosfat, Nitrat, Nitrit, Amoniak, Timbal, Klorida dan Sulfat.

Keberadaan plankton memegang peran penting dalam mempengaruhi produktifitas primer perairan sungai. Rosenberg (dalam Ardi, 2002) menyebutkan plankton bersifat toleran dan mempunyai respon yang berbeda terhadap perubahan kualitas perairan. Penggunaan plankton sebagai indikator kualitas lingkungan perairan dapat dipakai dengan mengetahui keragaman dengan keseragaman lainnya. Sehingga dengan adanya plankton yang berada pada lingkungan perairan tersebut akan memberikan reaksi terhadap kualitas perairan atas pencemaran yang terjadi. Berdasarkan uraian tersebut, peneliti ingin memberikan masukan atau rekomendasi ke Pemerintah Kota Jambi bahwasannya keberadaan plankton di badan air sangat erat kaitannya dengan kualitas air tersebut. Oleh karena penelitian ini bertujuan untuk mengetahui hubungan keanekaragaman plankton dengan parameter fisika kimia Sungai Batanghari dan hubungan keberadaan plankton dengan kualitas Sungai Batanghari.

\section{Metode Penelitian}

\subsection{Alat dan Bahan}

Alat yang digunakan dalam penelitian ini adalah Plankton Net, Mikroskop Cahaya, Ember Plastik, Water Quality Checker, Termometer Air Raksa, Sedgwick Rafter, Pipet tetes, Counter, Botol Sampel ukuran $30 \mathrm{ml}$, Botol Sampel ukuran 100ml, Botol Sampel ukuran 500ml, Botol Sampel ukuran $1000 \mathrm{ml}$, DO meter, Cawan Petri, Pipet Tetes, dan pH meter. Bahan yang diperlukan dalam penelitian ini adalah sampel Air Sungai Batanghari, Lugol dan $\mathrm{H}_{2} \mathrm{SO}_{4}$.

Data yang diperoleh pada penelitian ini berupa kepadatan individu plankton per liter. Untuk mendapatkan data ini digunakan alat Sedwick Rafter Chamber (SRC), sedangkan untuk mencari kelimpahan plankton digunakan rumus modifikasi dari Isnansetyo \& Kurniaty (1995), seperti berikut ini :

$$
\mathrm{N}=\frac{T}{L} x \frac{P}{p} x \frac{V}{v} x \frac{1}{W}
$$

\subsection{Keseragaman Plankton}

Dengan menggunakan data kelimpahan plankton tersebut kemudian dilakukan analisis data berupa indeks keseragaman plankton menurut Shannon-Wiener
(Krebs, 1989), adapun rumus dari masing-masing analisis data tersebut adalah sebagai berikut :

1. Indeks Keanekaragaman (diversitas) Shannon Wienner $\left(\mathrm{H}^{\prime}\right)$

Indeks keanekaragaman komunitas plankton pada tiga stasiun pengamatan dihitung lewat penggunaan rumus indeks keanekaragaman Shannon- Wiener berikut ini (Brower et al, 1990) :

$$
\mathrm{H}=\sum_{i=I}^{s} \text { pi Ln pi ...................... (2) }
$$

2. Indeks Ekuitabilitas (E)

Untuk mengetahui sebaran ataupun distribusi kelimpahan antar taksa dalam komunitas dilakukan uji indeks ekuibilitas yang disebut juga sebagai indeks keseragaman. Adapun rumus dari indeks ekuibilitas tersebut adalah sebagai berikut (Zar, 1999) :

$$
\text { Indeks Keseragaman }(E)=\frac{H \prime}{H \text { maks }} \text {. }
$$

3. Indeks Kesamaan (Similaritas) dari Sorensen Berapa besar kesamaan komposisi (keanekaragamn dan kelimpahan) plankton antar stasiun pengamatan dicari lewat menggunakan rumus indeks similaritas menurut Sorensen (Brower et al, 1990) seperti berikut ini :

$$
\mathrm{IS}=2 \mathrm{a} / \mathrm{S}_{1}+\mathrm{S}_{2} \times 100 \%
$$

\section{Hasil dan Pembahasan}

Hasil dan pembahasan dapat menampilkan data-data berupa tabel maupun gambar. Hasil harus didukung oleh referensi terkait ataupun dapat membandingkan dengan penelitian sebelumnya.

\subsection{Kondisi Perairan Sungai Batanghari Berdasarkan Parameter Fisik - Kimiawi \\ 3.1.1 Faktor Fisik}

Parameter fisika yang diukur selama penelitian adalah pengukuran suhu dan kekeruhan. Dimana pengukuran suhu perairan ini dilakukan langsung di tempat (insitu) pada tiap titik sampling perairan sungai Batanghari dan pengukuran parameter kekeruhan dilakukan di UPTD Laboratorium Dinas Lingkungan Hidup Daerah Provinsi Jambi. Hasil uji dari penelitian ini dapat dilihat pada tabel 4.1 sebagai berikut :

Tabel 1. Faktor Fisika yang Mempengaruhi Perairan

\begin{tabular}{llcccccc} 
No & Parameter & \multicolumn{2}{c}{ Titik I } & \multicolumn{2}{c}{ Titik II } & \multicolumn{2}{c}{ Titik III } \\
& & & & & & & \\
& & Pagi & Sore & Pagi & Sore & Pagi & Sore \\
& & & & & & & \\
\hline 1 & Suhu $^{\circ} \mathrm{C}$ & 28 & 29.7 & 28.2 & 28.7 & 29 & 28.9 \\
2 & Kekeruhan & 3.09 & 4.28 & 3.67 & 3.18 & 4.35 & 4.87
\end{tabular}




\subsubsection{Faktor Kimia}

Parameter kimia yang diukur secara langsung (insitu ) adalah pengukuran $\mathrm{pH}$ dan oksigen terlarut (DO). Parameter $\mathrm{pH}$ diukur menggunakan $\mathrm{pH}$ meter sedangkan untuk pengukuran parameter oksigen terlarut (DO) menggunakan metode titrasi yang dilakukan pada setiap titik sampling perairan sungai Batanghari dan untuk pengukuran parameter kimia lainnya seperti TDS, BOD, COD, Fosfat, Nitrat, Nitrit, Amoniak, Besi, Timbal, Klorida, dan Sulfat dibawa ke laboratorium Dinas Lingkungan Hidup Provinsi Jambi dengan masing-masing perlakuan sampel yang berbeda-beda sesuai SNI yang telah ditetapkan oleh Badan Standarisasi Nasional.

Dari beberapa parameter yang dianalisa memiliki korelasi dan saling mempengaruhi terhadap parameter lainnya. Adapun hasil pengukuran parameter kimia yang dianalisa dapat dilihat dari Tabel 4.2.

Tabel 2. Hasil Parameter Kimia yang mempengaruhi perairan

\begin{tabular}{|c|c|c|c|c|c|c|c|c|}
\hline \multirow[t]{2}{*}{ No } & \multirow[t]{2}{*}{ Parameter } & \multicolumn{2}{|c|}{ Titik I } & \multicolumn{2}{|c|}{ Titik II } & \multicolumn{2}{|c|}{ Titik III } & \multirow{2}{*}{$\begin{array}{l}\text { Baku } \\
\text { mutu }\end{array}$} \\
\hline & & Pagi & Sore & Pagi & Sore & Pagi & Sore & \\
\hline 1 & $\mathrm{pH}$ & 6.24 & 6.18 & 6.22 & 6.19 & 6.23 & 6.05 & $6-9$ \\
\hline 2 & TDS & 13 & 15 & 13 & 12 & 21 & 14 & 1000 \\
\hline 3 & BOD & 2.01 & 2.81 & 3.21 & 2.41 & 4.43 & 2.81 & 3 \\
\hline 4 & COD & 13 & 17 & 16 & 16 & 19 & 17 & 25 \\
\hline 5 & DO & 6.42 & 6.12 & 5.71 & 6.12 & 5.91 & 5.30 & $>4$ \\
\hline 6 & Fosfat & $<0.01$ & $<0.01$ & $<0.01$ & $<0.01$ & $<0.01$ & 0.081 & 0.2 \\
\hline 7 & Nitrat & 0.391 & 0.363 & 0.336 & 0.556 & 0.343 & 0.281 & 10 \\
\hline 8 & Nitrit & $<0.003$ & $<0.003$ & $<0.003$ & $<0.003$ & $<0.003$ & $<0.003$ & - \\
\hline 9 & Amoniak & 0.117 & 0.132 & 0.142 & 0.120 & 0.139 & 0.148 & - \\
\hline 10 & Timbal & $<0.05$ & $<0.05$ & $<0.05$ & $<0.05$ & $<0.05$ & $<0.05$ & 0.03 \\
\hline 11 & Klorida & 1.5101 & 2.2652 & 1.0067 & 1.2584 & 4.5305 & 2.0135 & - \\
\hline 12 & Sulfat & $<0.4$ & $<0.4$ & $<0.4$ & 1.6 & 1.8 & 1.6 & - \\
\hline
\end{tabular}

\subsection{Jenis-Jenis Fitoplankton di Perairan Sungai Batanghari}

Dari hasil penelitian yang telah dilakukan di Sungai Batanghari Kota Jambi diperoleh 4 kelas fitoplankton yang teridentifikasi yaitu Kelas Bacillariophyceae, Kelas Chlorphyceae, Kelas Cyaniphyceae, dan Kelas Euglenophyceae. Dari keempat kelas fitoplankton tersebut dapat dilihat pada gambar 1. Dari 4 kelas tersebut diperoleh jumlah total spesies fitoplankton sebanyak 15 spesies. Pada kelas Bacillariophyceae diperoleh 10 spesies yaitu : Achnanthes sp, Eunotia sp, Fragilaria sp, Gomphonema $s p$, Melosira sp, Navicula sp, Nitzchia sp, Pinnularia sp, Pleurosigma $s p$, dan Surirella $s p$. Selanjutnya untuk kelas Chlorophyceae ada 3 spesies yang terindetifikasi yaitu : Closterium sp, Rhizoclonium sp, dan Spirogyra $s p$. Untuk kelas Cyanophyceae ada satu spesies yang terindikasi yaitu Oscillatoria $s p$. Selanjutnya untuk kelas Euglenophyceae teridentifikasi satu spesies yaitu Trachelomonas sp.

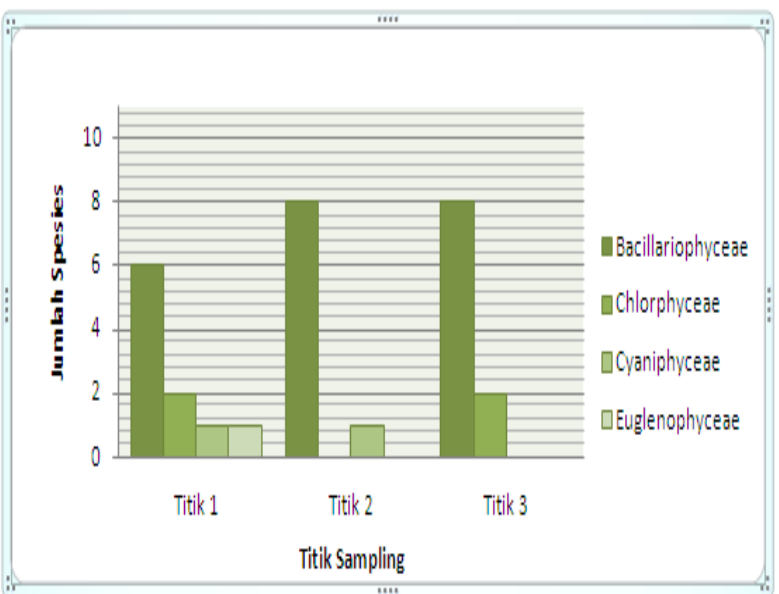

Gambar 1. Jenis-jenis Fitoplankton di Sungai Batanghari

\subsection{Jenis-Jenis Zooplankton di Perairan Sungai Batanghari}

Dari hasil penelitian yang telah dilakukan di Sungai Batanghari Kota Jambi diperoleh 2 kelas fitoplankton yang teridentifikasi yaitu Kelas Protozoa dan Rotifera. 
Dari kedua kelas zooplankton tersebut dapat dilihat pada gambar 2.

\subsection{Hubungan Keberadaan Plankton dengan Kualitas Sungai Batanghari}

Hasil data plankton yang telah didapat dalam penelitian ini maka dapat dilihat kualitas sungai batanghari berdasarkan tingkat pencemaran yang ada di perairan sungai batanghari tersebut. Tingkat pencemaran dapat dihitung dengan menggunakan indeks saprobik.

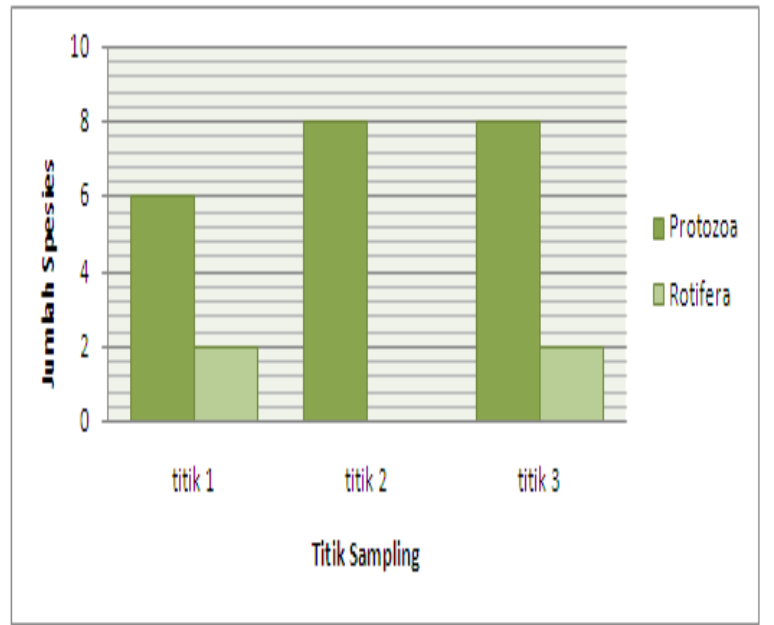

Gambar 2. Jenis-jenis Zooplankton di Sungai Batanghari

Indeks ini merupakan indeks untuk menentukan tingkat pencemaran disuatu perairan dengan menentukan koefisien saprobitasnya yaitu messo saprobik, poli saprobik atau oligo saprobik. Adapun rumus indeks saprobik dengan persamaan (Maresi et al. 2015) dan hasil perhitungannya pada tabel 3 berikut ini :

$\mathrm{X}=\frac{C+3 D-B-3 A}{A+B+C+D}$

Keterangan :

$\mathrm{X}=$ Koefisien Saprobik (-3sampai 3)

$\mathrm{A}=$ Jumlah Organisme divisi Cyanophyta

$\mathrm{B}=$ Jumlah Organisme divisi Chlorophyta,

Bacillariophyta

$\mathrm{C}=$ Jumlah Organisme divisi Dynophyta

D = Jumlah Organisme divisi Chrysophyta

Nilai indeks saprobitas yang diperoleh dari hasil analisis diatas berdasarkan hubungan antara koefisien saprobitas perairan (X) dengan tingkat pencemaran perairan terkait komunitas plankton terklasifikasikan terjadinya pencemaran tingkat berat atau $\alpha$ mesosaprobik dengan nilai saprobik -1.14.

Tingkat $\alpha$-mesosaprobik memiliki ciri-ciri komunitas BOD yang tinggi dan munculnya fitoplankton Cyanophyceae. Hal ini sesuai dengan hasil yang didapatkan bahwa jenis Cyanophyceae dan Bacillariophyceae memiliki jenis spesies yang tinggi.
Tabel 3. Indeks Saprobitas Fitoplankton

\begin{tabular}{clc}
\hline Kode & \multicolumn{1}{c}{ Kelas } & Jumlah Jenis \\
\hline A & Cyanophyta & 0 \\
B & Chlorophyta, Bacillariophyta & 13 \\
C & Dinophyta & 0 \\
D & Chrysophyta & 0 \\
& X $=0+(3.0)-13-(3.1)$ & \\
& $=\frac{0+0-13-3}{1+13+0=0}$ & \\
& $=-1.14$ & \\
& Nilai Saprobik ( X )
\end{tabular}

Pencemaran bahan organik yang terjadi dapat disebabkan karena adanya limbah domestik yang berasal dari aktifitas rumah tangga dimana masih banyak terdapat jamban tempat kegiatan mandi dan mencuci di pinggiran Sungai Batanghari. Berdasarkan aktifitas tersebut, tentunya akan menghasilkan limbah organik berupa kotoran tinja, sisa makanan (sampah rumah tangga), tumbuh-tumbuhan yang mati dan hewan yang mati yang terdekomposisi yang mengakibatkan terjadinya penurunan kualitas perairan. Hal ini sesuai dengan angka BOD yang berada di atas baku mutu yaitu $4.43 \mathrm{mg} /$ liter. Dari hasil indeks saprobik yang didapat menunujukkan ketidaksesuaian antara parameter fisika kimia yang didapat. Hasil parameter fisika kimia yang didapat menunjukkan kadar yang masih dibawah baku mutu air yang disyaratkan sesuai PP 82 Tahun 2001, sedangkan hasil identifikasi plankton yang didapat menunjukkan bahwa adanya tingkat pencemaran berat di Sungai Batanghari Kota Jambi. Hal ini dikarenakan pengambilan sampel plankton dilakukan pada pagi dan sore, sedangkan plankton akan berfotosintesis sempurna pada siang hari dengan bantuan sinar matahari, dan dipastikan plankton yang teridentifikasi baik itu fitoplankton maupun zooplankton akan lebih beragam sehingga kualitas Sungai Batanghari baik.

\section{Kesimpulan}

Hasil penelitian yang telah dilakukan di Sungai Batanghari Kota Jambi dapat disimpulkan sebagai berikut :

1. Korelasi beberapa parameter fisika kimia terhadap fitoplankton sebagai berikut :

a. pH, COD, Fosfat, Nitrit, Timbal dan Klorida berkorelasi sedang terhadap fitoplakton.

b. TDS, BOD, DO, Nitrat dan Amonian berkorelasi lemah terhadap fitoplankton

c. Suhu berkorelasi kuat terhadap fitoplankton

2. Korelasi beberapa parameter fisika kimia terhadap zooplankton, sebagai berikut :

a. pH, TDS, BOD, COD, DO, Fosfat, Nitrat, Nitrit, Timbal dan Klorida berkorelasi sangat lemah terhadap zooplankton 
b. Amoniak dan Kekeruhan berkorelasi sedang terhadap zooplankton

3. Hubungan antara keberadaan plankton dengan kualitas sungai batanghari dilihat dari tingkat pencemaran yang ada, diperoleh koefisien saprobik yaitu $-1,14$ yang berarti kondisi perairan sungai batanghari kota jambi berada di fase $\alpha_{-}$Mesosaprobik (tingkat pencemar berat).

\section{Daftar Pustaka}

Odum, E. P. (1994). Dasar-Dasar Ekologi. Penerjemah: Tjahjono Samingan, Yogyakarta: Edisi Ketiga, Gajah Mada Univerdity-Press

Romimohtarto, K. (2001). Biologi Laut Ilmu Pengetahuan Tentang Biota Laut. Jakarta: Penerbit Djambatan

BSN. (2004). Standarisasi Nasional Indonesia (SNI) tentang Cara Uji Derajat Keasaman (pH) Dengan Menggunakan Alat $\mathrm{pH}$ Meter. Badan Standarisasi Nasional (BSN), Jakarta

BSN. (2004). Standarisasi Nasional Indonesia (SNI) tentang Cara Uji Kebutuhan Oksigen BIokimia Biochemical Oxygen Demand (BOD). Badan Standarisasi Nasional (BSN), Jakarta
BSN. (2004). Standarisasi Nasional Indonesia (SNI) tentang Cara Uji Kebutuhan Oksigen Kimiawi (KOK) Refluks Terbuka Dengan Refluks Terbuka Secara Titrimetri. Badan Standarisasi Nasional (BSN), Jakarta

BSN. (2005). Standarisasi Nasional Indonesia (SNI) tentang Cara Uji Kadar Fosfat Dengan Spektrofotometer Secara Asam Askorbat. Badan Standarisasi Nasional (BSN), Jakarta

BSN. (2005). Standarisasi Nasional Indonesia (SNI) tentang Cara Uji Kadar Padatan Terlarut Total Secara Gravimetri. Badan Standarisasi Nasional (BSN), Jakarta

BSN. (2005). Standarisasi Nasional Indonesia (SNI) tentang Cara Uji Besi (Fe) Dengan Spektrofometri Serapan Atom. Badan Standarisasi Nasional (BSN), Jakarta

BSN. (2004). Standarisasi Nasional Indonesia (SNI) tentang Cara Uji Sulfat, $\mathrm{SO}_{4}{ }^{2-}$ Secara Turbidimetri. Badan Standarisasi Nasional (BSN), Jakarta

BSN. (2004). Standarisasi Nasional Indonesia (SNI) tentang Metode Uji Ion Klorida Dalam Air. Badan Standarisasi Nasional (BSN), Jakarta

BSN. (2011). Standarisasi Nasional Indonesia (SNI) tentang Cara Uji Nitrat Dengan Spektrofotometer UV - Visible Secara Reduksi Cadmium. Badan Standarisasi Nasional (BSN), Jakarta 